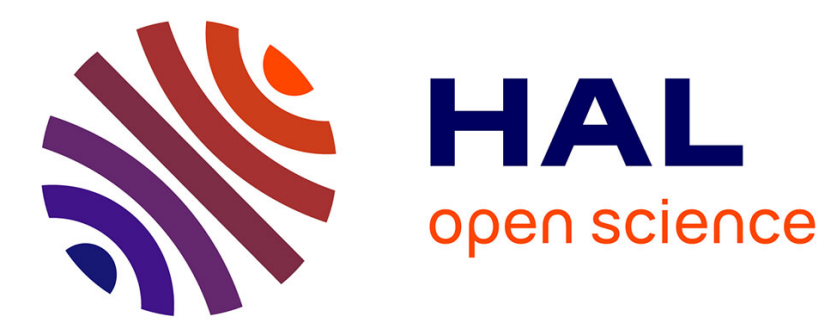

\title{
Fault tolerant oxygen control of a diesel engine air system
}

Rainer Nitsche, Matthias Bitzer, Mahmoud El Khaldi, Gérard Bloch

\section{To cite this version:}

Rainer Nitsche, Matthias Bitzer, Mahmoud El Khaldi, Gérard Bloch. Fault tolerant oxygen control of a diesel engine air system. IFAC Symposium Advances in Automotive Control, AAC 2010, Jul 2010, Munich, Germany. pp.CDROM. hal-00475414

\section{HAL Id: hal-00475414 https://hal.science/hal-00475414}

Submitted on 21 Apr 2010

HAL is a multi-disciplinary open access archive for the deposit and dissemination of scientific research documents, whether they are published or not. The documents may come from teaching and research institutions in France or abroad, or from public or private research centers.
L'archive ouverte pluridisciplinaire HAL, est destinée au dépôt et à la diffusion de documents scientifiques de niveau recherche, publiés ou non, émanant des établissements d'enseignement et de recherche français ou étrangers, des laboratoires publics ou privés. 


\title{
Fault Tolerant Oxygen Control of a Diesel Engine Air System
}

\author{
Rainer Nitsche* Matthias Bitzer* Mahmoud El Khaldi** \\ Gérard Bloch** \\ * Robert Bosch GmbH, Dept. CR/AEH3 - Control Theory Group, \\ P.O. Box $300240, D-704$ 42 Stuttgart, Germany \\ (e-mail: \{rainer.nitsche,matthias.bitzer2\}@de.bosch.com) \\ ** Université Henri Poincaré, Nancy 1, Centre de Recherche en \\ Automatique de Nancy (CRAN), CNRS UMR 7039, Nancy, France \\ (e-mail: gerard.bloch@esstin.uhp-nancy.fr)
}

\begin{abstract}
This paper is devoted to the fault tolerant control problem of a Diesel engine air system having a jammed Exhaust Gas Recirculation (EGR) valve. The fault tolerant control is based on replaning the trajectory in order to track a new controlled variable which is the oxygen concentration in the intake manifold instead of the fresh air mass flow. The trajectory planning is based on an inverse model approach, utilizing the fundamental thermodynamic relations of the air system.
\end{abstract}

Keywords: Fault tolerant control, Diesel engine, Air system, Model-based trajectory planning

\section{INTRODUCTION}

Diesel engines have made significant progress in terms of performance over the last years and have become very popular and increasingly attractive for passenger cars thanks to their low fuel consumption and high torque at low speed. However, they are significant contributors to overall emissions, especially of nitrogen oxides $\left(\mathrm{NO}_{\mathrm{x}}\right)$ and particulate matter (PM, also called soot).

The air system of a Diesel engine, shown in Figure 1, is responsible for introducing air into the engine cylinders in order to ensure the fuel combustion. The functioning of the air system is the following. Fresh air entering the air system is compressed by the compressor unit of the turbocharger. The air leaves the compressor with higher pressure, and its temperature increases as a result of the compression. A charge air cooler (CAC), not represented in the Figure, cools down the compressed air before it reaches the throttle valve (TVA; or throttle blade, TB). The fresh air is then mixed with recirculated exhaust gas in the intake manifold and the mixture goes into the engine ${ }^{1}$. The waste of the combustion is then expelled from the engine, and a part of the exhaust gas is sent to the intake manifold over the exhaust gas recirculation (EGR) valve to be mixed with fresh air. The rest of the exhaust gas passes through the variable nozzle turbine (VNT) unit of the turbocharger, where its energy is used to drive the compressor wheel via the shaft, which connects the turbine and the compressor wheels.

The main purpose of the exhaust gas recirculation is to reduce the nitrogen oxide $\left(\mathrm{NO}_{\mathrm{x}}\right)$ emissions. Indeed, mixing the exhaust gas with the fresh air reduces the oxygen concentration in the intake manifold. Thus, since there is

\footnotetext{
1 In this paper, the term engine stands for the combustion chamber (cylinders) and not for the overall engine.
}

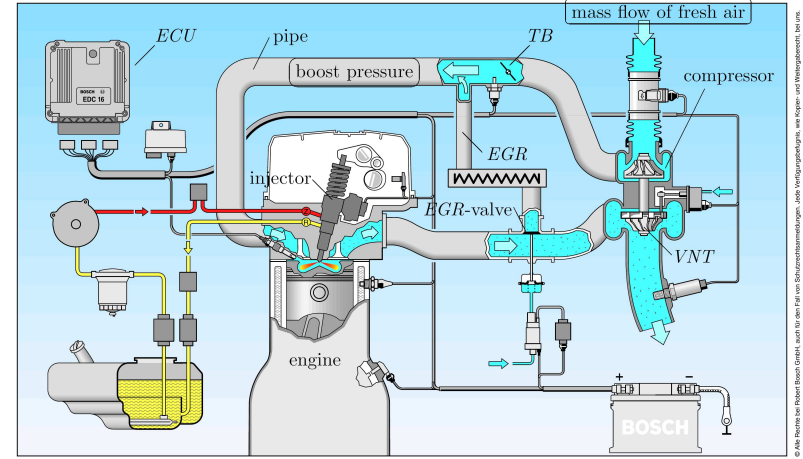

Figure 1. Air system of the Diesel engine.

less oxygen to react with the fuel in the engine, fewer $\mathrm{NO}_{\mathrm{x}}$ are produced during the combustion. On the other hand, a lower oxygen rate in the engine leads to an incomplete combustion, and induces the production of more carbon hybrid and particulate matter (PM).

The EGR valve is the main component in the exhaust gas recirculation system. The valve is located between the intake and exhaust manifolds, then a part of the exhaust gas can flow back into the engine. The rate of exhaust gas mixed with the fresh air in the intake manifold is controlled by acting on the cross section area of the valve. However, as any physical system, EGR valves are subject to faults. The main fault that can affect an EGR valve is the blocking at a certain position, which increases the emissions of pollutants.

The paper will deal thus with the fault tolerant control (FTC) of the Diesel engine air system having a jammed EGR valve, with the aim of reducing pollutant emissions. Section 2 introduces the overall faultless control and fault tolerant control structures of the air system. The different 
parts of the fault tolerant control are described in Sections 3,4 and 5. Some simulations results are presented in Section 6 , before concluding remarks.

\section{AIR SYSTEM CONTROL STRUCTURE}

\subsection{System models and faultless control structure}

The air system is controlled by using a particular modelbased approach. Such an approach performs three tasks: planning of trajectories with bounding conditions, calculation of nominal control variables through the inverted system and stabilization of the system around the desired trajectory by closed-loop control. The advantages include the consideration of physical coupling and effects, the simultaneous control of desired values and the fulfillment of high dynamic requirements.

A schematic representation of the air system is presented in Figure 2 with the main describing variables.

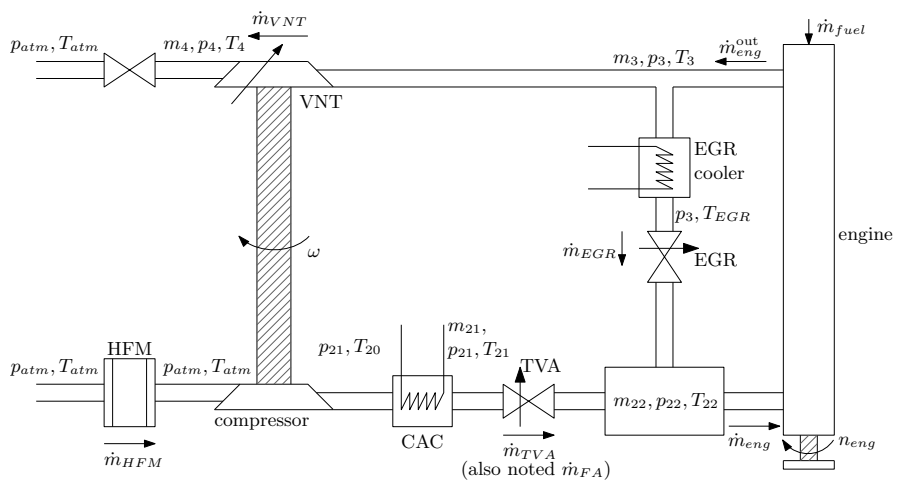

Figure 2. Schematic representation of the air path.

This system is modelled with the so-called Robert Bosch Standard Simulation Library (RBSL). The resulting air system RBSL model consists of four volumes connected by algebraic relations and has eleven states:

- the boost pressure $p_{21}$,

- the air mass in the boost pressure volume $m_{21}$,

- the intake manifold pressure $p_{22}$

- the air mass in the intake manifold $m_{22}$,

- the mass of oxygen in the intake manifold $m_{O_{2}, 22}$,

- the rate of fresh air in the intake manifold $r_{F A, 22}$,

- the exhaust manifold pressure $p_{3}$,

- the air mass in the exhaust manifold $m_{3}$,

- the downstream pressure of the turbine (VNT) $p_{4}$,

- the downstream gas mass of the VNT $m_{4}$,

- the angular speed of the turbocharger $\omega$.

The manipulated variables, i.e. the control inputs, are:

- the effective area of the throttle valve (TVA) $A_{T V A}^{\text {eff }}$,

- the effective area of the EGR valve $A_{E G R}^{e f f}$,

- the effective area of the VNT $A_{V N T}^{e f f}$,

and the controlled variables:

- the fresh air (FA) mass flow $\dot{m}_{F A}$,

- the rate of EGR gas in the intake manifold $r_{E G R, 22}$,

- the boost pressure $p_{21}$.

The model-based control architecture of the air-path is shown in Figure 3. It consists of three modules:
- The Air System Model (ASMod) estimates the air system signals that cannot be measured with the available sensors. From the modelling of the system, it also dynamically corrects the measured signals, when the measured value is in the range of low sensitivity of the sensor. The outputs of the ASMod are used by the model-based controllers, briefly described next.

- The Model-based Boost Control (MBC) controls the boost pressure $p_{21}$ by manipulating the VNT input $A_{V N T}^{e f f}$. The two-degree of freedom design is based on an inverse model of the turbocharger for the feedforward part of the controller and a PIstructure for the feedback part. The MBC uses a family of PID controllers, each of them providing a satisfactory control for a particular operating point (gain scheduling). It can work either in open or closed loop, depending on the operating point. In closed loop mode, the MBC regulates the boost pressure to avoid getting too high pressure that may damage the turbocharger.

- The Model-based Charge Control (MCC) controls the fresh air mass flow $\dot{m}_{F A}$ and/or the EGR rate $r_{E G R}$, depending on the operating point, by acting on the throttle and EGR valves. Again, a two-degree of freedom design is used. The MCC contains Kalman filters which estimate the current areas of the throttle and EGR valves, an inverse model of the intake manifold to calculate the desired areas, and PI-controllers.

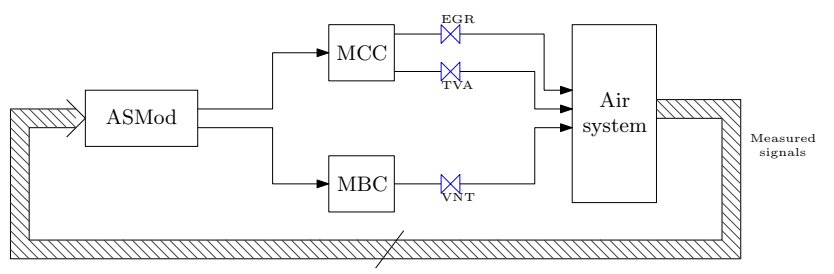

Figure 3. Current air system control unit.

\subsection{Fault tolerant control structure}

The fault-tolerant control strategy aims at keeping this control structure in the faulty case, and not designing new controllers. As the considered fault is an actuator fault (EGR valve jam), there is no possibility to adapt the controller by simply changing its parameters for the faulty case. Instead, alternative actuators which have similar interactions with the system have to be used (Blanke et al., 2006). The alternative actuator used here is the throttle valve, which is controlled by the MCC.

For the faulty case, it is furthermore desired to switch to a new controlled variable which is the oxygen concentration in the intake manifold, because this variable is directly linked with the pollutants emissions.

The resulting closed loop structure is depicted in Figure 4 with references to the main corresponding equations. The first block, detailed in Section 3, calculates the desired oxygen concentration in the intake manifold $r_{O_{2}, E G R}^{\mathrm{d}}$. In order to track this setpoint, the second task, detailed in Section 4, calculates, by inversion of the intake manifold model, the new desired fresh air mass flow $\dot{m}_{F A}^{\mathrm{d} *}$. A reachability analysis (Section 5 ) allows the MCC to receive $\dot{m}_{F A}^{\mathrm{d}, \text { final }}$ as input. 


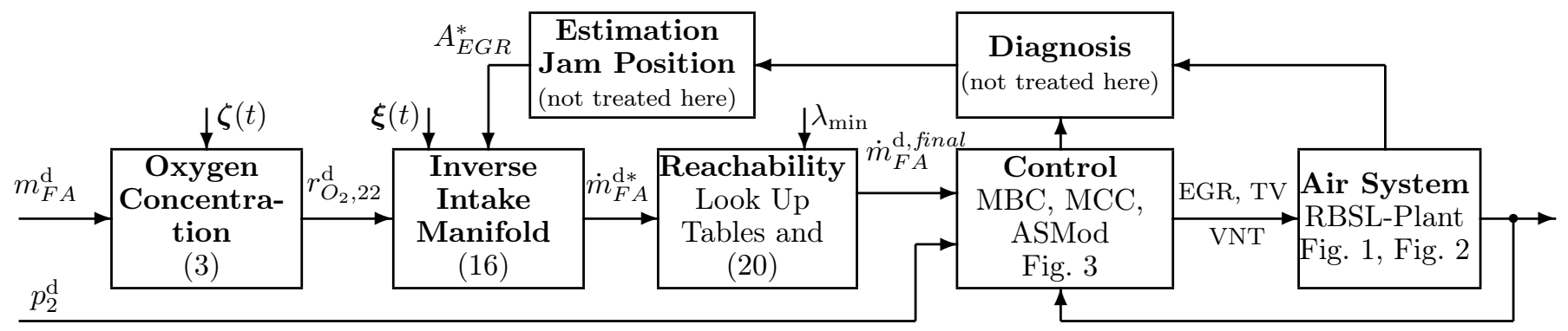

Figure 4. Overall closed-loop structure of the proposed fault tolerant control.

The known time variant parameters required for $(3)$ and (16) are collected in the vectors $\boldsymbol{\zeta}(t)$ and $\boldsymbol{\xi}(t)$. Note that the diagnosis task and the estimation of the jam positition (Scheu, 2008) are not treated in this paper. Therefore, this jam position is assumed here to be perfectly known.

\section{NEW CONTROLLED VARIABLE}

The new controlled variable, i.e., the oxygen concentration $r_{\mathrm{O}_{2}, 22}$ in the intake manifold, is the ratio of the oxygen mass flow $\dot{m}_{\mathrm{O}_{2}, \text { eng }}$ over the total gas mass flow $\dot{m}_{e n g}$, going in the engine:

$$
r_{O_{2}, 22}=\frac{\dot{m}_{O_{2}, e n g}}{\dot{m}_{\text {eng }}},
$$

or, as the gas entering the engine is exclusively composed of fresh air and EGR gas:

$$
r_{O_{2}, 22}=\frac{\dot{m}_{F A} r_{O_{2}, F A}+\dot{m}_{E G R} r_{O_{2}, E G R}}{\dot{m}_{F A}+\dot{m}_{E G R}},
$$

where $r_{O_{2}, F A}$ and $r_{O_{2}, E G R}$ are the oxygen ratios in the fresh air and EGR gas, respectively.

This gives the desired oxygen concentration in the intake manifold:

$$
r_{O_{2}, 22}^{\mathrm{d}}=\frac{\dot{m}_{F A}^{\mathrm{d}} r_{O_{2}, F A}+\dot{m}_{E G R}^{\mathrm{d}} r_{O_{2}, E G R}^{\mathrm{d}}}{\dot{m}_{F A}^{\mathrm{d}}+\dot{m}_{E G R}^{\mathrm{d}}},
$$

where $\dot{m}_{F A}^{\mathrm{d}}$ is the desired fresh air mass flow (given by the Electronic Control Unit, ECU), and $\dot{m}_{E G R}^{\mathrm{d}}$ is the desired EGR mass flow and $r_{O_{2}, E G R}^{\text {d }}$ the desired oxygen ratio in the EGR gas, which can be calculated in the following way.

The enthalpy balance in the intake manifold can be written as

$$
c_{p, M i x} \dot{m}_{22} T_{22}=c_{p, E G R} \dot{m}_{E G R}^{\mathrm{d}} T_{E G R}+c_{p, F A} \dot{m}_{F A}^{\mathrm{d}} T_{21},
$$

where $c_{p, M i x}, c_{p, E G R}$ and $c_{p, F A}$ are the heating capacities of the mixture (EGR gas + fresh air), EGR gas and fresh air, respectively, $T_{22}$ is the intake manifold temperature, $T_{E G R}$ the EGR gas temperature, and $T_{21}$ the temperature of the fresh air over the throttle valve.

Assuming that the upstream pressure $p_{21}$ of the throttle valve is the same as the pressure $p_{22}$ in the intake manifold (Scheu, 2008), the ideal gas law gives:

$$
\dot{m}_{22} T_{22}=\frac{p_{22} \dot{V}_{e n g}}{R_{M i x}}=\frac{p_{21}^{\mathrm{d}} \dot{V}_{e n g}}{R_{M i x}},
$$

where $\dot{V}_{\text {eng }}$ is the variation of the engine volume, and $R_{M i x}$ is the gas constant of the mixture (EGR gas + fresh air).
Therefore, the desired EGR mass flow $\dot{m}_{E G R}^{\mathrm{d}}$ needed to compute (3) can be estimated from (4) and (5) by

$$
\hat{\dot{m}}_{E G R}^{\mathrm{d}}=\frac{c_{p, M i x} \frac{p_{21}^{\mathrm{d}} \dot{V}_{e n g}}{R_{M i x}}-c_{p, F A} \dot{m}_{F A}^{\mathrm{d}} T_{21}}{c_{p, E G R} T_{E G R}} .
$$

Moreover, with the overall mass balance and the oxygen mass balance in the engine, the desired oxygen ratio $r_{\mathrm{O}_{2}, E G R}^{\mathrm{d}}$ in the EGR gas, also needed to compute (3), can be obtained by:

$$
r_{O_{2}, E G R}^{\mathrm{d}}=r_{O_{2}, F A} \frac{\dot{m}_{F A}^{\mathrm{d}}-r_{\text {stoic }} \dot{m}_{f u e l}}{\dot{m}_{F A}^{\mathrm{d}}+\dot{m}_{f u e l}},
$$

where $r_{\text {stoic }}$ is the stoichiometric air to fuel coefficient and $\dot{m}_{f u e l}$ is the amount of injected fuel into the engine.

\section{MODEL-BASED TRAJECTORY PLANNING OF THE DESIRED FRESH AIR MASS FLOW}

According to Figure 4, the desired oxygen concentration in the intake manifold can now be used to calculate the new desired fresh air mass flow $\dot{m}_{F A}^{\mathrm{d} *}$ in the faulty case. In other words, a new trajectory for the desired fresh air mass flow has to be planned, depending on the known jam-position of the EGR valve and the desired oxygen concentration in the intake manifold. For this, a model-based approach is used, where the inversion of the intake manifold model is based on a flatness analysis in the sense of Fliess et al. (1992) and Rothfuß et al. (1997).

\subsection{Inversion of the intake manifold model}

For a model-based trajectory planning, the dynamics of the intake manifold can be described with the following state, control input, and output definition:

$$
\boldsymbol{x}=\left[m_{\mathrm{O}_{2}, 22}, m_{\overline{\mathrm{O}_{2}}, 22}\right]^{T}, \quad u=\dot{m}_{F A}, \quad y=r_{\mathrm{O}_{2}, 22},
$$

where $m_{\mathrm{O}_{2}, 22}$ and $m_{\overline{\mathrm{O}_{2}}, 22}$ are respectively the masses of oxygen and all other gases in the intake manifold, with the external time-varying parameters

$$
\boldsymbol{q}=\left[\dot{m}_{E G R}, \dot{m}_{e n g}, r_{O_{2}, F A}, r_{O_{2}, E G R}, n_{e n g}\right]^{T},
$$
with $n_{\text {eng }}$ the engine speed.

State Equations. The first state equation is obtained by considering the mass flow balance in the intake manifold:

which leads to

$$
\dot{m}_{O_{2}, 22}=\dot{m}_{O_{2}, E G R}+\dot{m}_{O_{2}, F A}-\dot{m}_{O_{2}, e n g},
$$

$$
\dot{m}_{O_{2}, 22}=\dot{m}_{E G R} r_{O_{2}, E G R}+\dot{m}_{F A} r_{O_{2}, F A}-\dot{m}_{e n g} r_{O_{2}, 22} \text {, }
$$


and finally to

$$
\dot{x}_{1}=q_{1} q_{4}+u q_{3}-y q_{2} .
$$

The second state equation is obtained as follows:

$$
\dot{m}_{\overline{O_{2}}, 22}=\dot{m}_{22}-\dot{m}_{O_{2}, 22}=\dot{m}_{E G R}+\dot{m}_{F A}-\dot{m}_{e n g}-\dot{x}_{1},
$$

leading to

$$
\dot{x}_{2}=q_{1}+u-q_{2}-\dot{x}_{1}
$$

or

$$
\dot{x}_{2}=q_{1}+u-q_{2}-\left(q_{1} q_{4}+u q_{3}-y q_{2}\right) .
$$

Output Equation. The system output $y$ is equal to

which gives

$$
y=r_{\mathrm{O}_{2}, 22}=\frac{m_{\mathrm{O}_{2}, 22}}{m_{\mathrm{O}_{2}, 22}+m_{\overline{\mathrm{O}_{2}}, 22}},
$$

$$
y=\frac{x_{1}}{x_{1}+x_{2}} .
$$

System Inversion. The input $u$ can be expressed as a function of the output $y$ and its successive derivatives. Indeed, (12) gives

$$
x_{1}=y\left(x_{1}+x_{2}\right)=y m_{22} \text {. }
$$

As $m_{22}=\frac{V_{22}}{R_{M i x} f\left(n_{\text {eng }}\right)} \dot{m}_{\text {eng }}$, where the known function $\frac{V_{22}}{R_{\text {Mix }}\left(n_{\text {eng }}\right)}$, with $V_{22}$ the intake manifold volume, considers the amount of air consumption for the engine, the first state becomes

$$
x_{1}=\frac{V_{22}}{R_{M i x} f\left(n_{\text {eng }}\right)} q_{2} y .
$$

Moreover, (12) gives

and

$$
x_{2}=\frac{x_{1}}{y}-x_{1}
$$

$$
\dot{x}_{2}=\frac{\dot{x}_{1} y-\dot{y} x_{1}}{y^{2}}-\dot{x}_{1} .
$$

Identifying (14) with (11) leads to

$$
q_{1}+u-q_{2}=\frac{\dot{x}_{1} y-\dot{y} x_{1}}{y^{2}} .
$$

Then, using (10) and (13), simple calculations give finally the output $u$ as

$$
u=\frac{q_{1}\left(q_{4}-y\right)-\frac{V_{22}}{R_{M i x} f\left(n_{e n g}\right)} q_{2} \dot{y}}{y-q_{3}} .
$$

New desired fresh air mass flow. This leads directly to the expression of the new desired fresh air mass flow:

$$
\begin{aligned}
\dot{m}_{F A}^{\mathrm{d} *}=\frac{\left(r_{\mathrm{O}_{2}, E G R}-r_{\mathrm{O}_{2}, 22}^{d}\right) \dot{m}_{E G R}}{r_{O_{2}, 22}^{d}-r_{O_{2}, F A}} & \\
& -\frac{\frac{V_{22}}{R_{M i x} \mathrm{f}\left(n_{e n g}\right)} \dot{m}_{e n g} \dot{r}_{\mathrm{O}_{2}, 22}^{\mathrm{d}}}{r_{\mathrm{O}_{2}, 22}^{d}-r_{O_{2}, F A}} .
\end{aligned}
$$

To compute (16), one needs to calculate the EGR mass flow $\dot{m}_{E G R}$, the oxygen concentration $r_{O_{2}, E G R}$ in the EGR gas and the mass flow $\dot{m}_{\text {eng }}$ going into the engine.

\subsection{EGR mass flow}

To calculate the mass flow over the jammed EGR valve, the orifice equation can be used:

$$
\dot{m}_{E G R}=p_{3} A_{E G R}^{*} \sqrt{\frac{2 \Pi^{-1}\left(1-\Pi^{-1}\right)}{T_{\text {cooler }, \text { out }}^{E G R} R}},
$$

where

$$
\Pi=\frac{p_{3}}{p_{22}}, \quad T_{\text {cooler }, \text { out }}^{E G R}=T_{3}-\eta_{H E}\left(T_{3}-T_{\text {coolingfluid }}\right),
$$

and $A_{E G R}^{*}$ is the effective area of the EGR valve estimated by a Kalman filter of a diagnosis algorithm developed by Scheu (2008).

\subsection{Calculation of the engine mass flow}

To estimate the engine mass flow $\dot{m}_{\text {eng }}$, the following equation can be used:

$$
\dot{m}_{\text {eng }}=\frac{p_{22}^{\text {meas }}}{T_{22}^{\text {ASMod }} R} \frac{V_{\text {eng }}}{2} \psi\left(n_{\text {eng }}\right),
$$

where $p_{22}^{\text {meas }}$ is the measured intake manifold pressure, $T_{22}^{\text {ASMod }}$ is the ASMod estimation of the intake manifold temperature, $p_{22}^{\text {meas }}$ is the measured intake manifold pressure, $T_{22}^{\mathrm{ASM} M o d}$ is the ASMod estimation of the intake manifold temperature, $V_{\text {eng }}$ is the engine volume, $\psi\left(n_{\text {eng }}\right)$ is a correction term representing the engine volumetric efficiency, $R$ is the perfect gases constant, and $c_{p}$ the heating capacity of the intake gas at constant pressure is the measured intake manifold pressure.

\subsection{Calculation of the oxygen rate in the exhaust gas}

To estimate the oxygen rate $r_{O_{2}, E G R}$ in the exhaust gas, (7) can be used by replacing the desired values by the real values:

$$
r_{O_{2}, E G R}=r_{O_{2}, F A} \frac{\dot{m}_{F A}^{\text {meas }}-r_{\text {stoic }} \dot{m}_{\text {fuel }}}{\dot{m}_{F A}^{\text {meas }}+\dot{m}_{\text {fuel }}},
$$

with $r_{\text {stoic }}=14.5$.

4.5 Test of the model-based trajectory planning in the faultless case

Equation (16) has been implemented in the simulation environment and tested using a special test cycle in the faultless case. Since the faultless case is considered, the old (given by the ECU) and the new desired fresh air mass flow should be equal. Figure 5 draws a comparison of these two signals, which are shown most of the time equal. Therefore, it can be assessed that the model-based trajectory planning of the desired fresh air mass flow is correct.

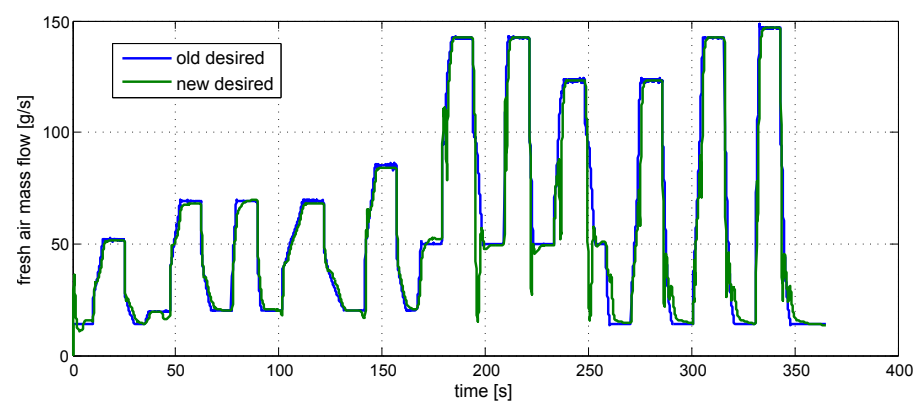

Figure 5. Old $\dot{m}_{F A}^{\mathrm{d}}$ and new $\dot{m}_{F A}^{\mathrm{d} *}$ desired fresh air mass flows, in the faultless case. 


\section{REACHABILITY ANALYSIS OF THE DESIRED FRESH AIR MASS FLOW AND CLOSED-LOOP STRUCTURE}

The next step (see Figure 4) is to check if the values of the calculated new desired fresh air mass flow $\dot{m}_{F A}^{\mathrm{d} *}(16)$ are physically reachable (higher limit), and not below a certain limit (lower limit). This reachability analysis is decribed below.

Higher limit. The fresh air mass flow depends on several variables: engine speed, injected fuel quantity, EGR valve position, turbocharger VNT position, TVA position. However, it is obvious that the throttle valve (TVA) has to be fully opened to reach a maximal value. Therefore, a look-up table is created with only these 4 first variables as inputs, and the maximal reachable fresh air mass flow as output. The output values of this table are the fresh air mass flow values obtained in the faultless case from appropriate simulation runs, where

- the engine speed varies between 1500rpm and $4000 \mathrm{rpm}$ with a step of 250 ;

- the injected fuel quantity varies between $10 \mathrm{mg} / \mathrm{hub}$ and $55 \mathrm{mg} /$ hub with a step of 5 ;

- the EGR valve position varies between $0 \%$ (fully opened) and $100 \%$ (fully closed) with a step of 10 ;

- the VNT position varies between $0 \%$ and $100 \%$ with a step of 2 .

Lower limit. The lower limit of the fresh air mass flow is governed by the air to fuel ratio $\lambda$ which has to be greater than a certain limit $\lambda_{\min }$ :

$$
\lambda=\frac{\dot{m}_{F A}}{r_{\text {stoic }} \dot{m}_{\text {fuel }}} \geq \lambda_{\min }=1.3,
$$

where $r_{\text {stoic }}=14.5$ is the stoichiometric air/fuel ratio.

Figure 6 shows an example of the desired fresh air mass flow in the faultless case, with the maximal reachable and minimal allowed values.

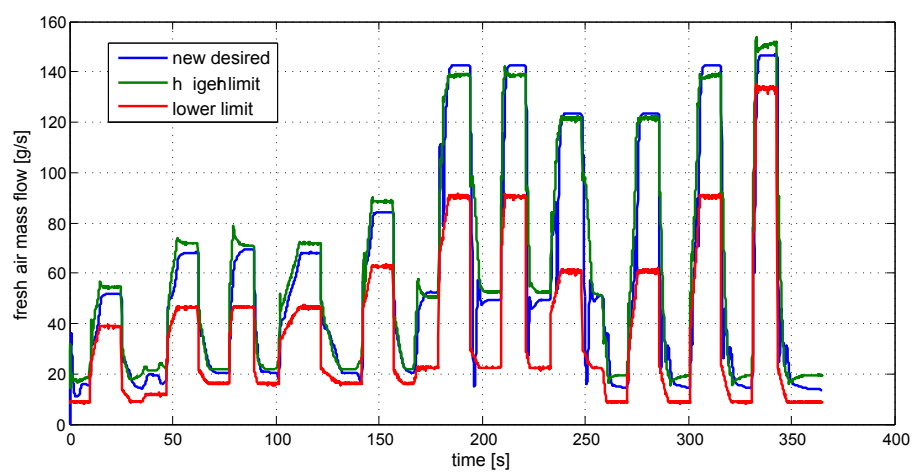

Figure 6 . The new desired fresh air mass flow $\dot{m}_{F A}^{\mathrm{d} *}$, with the maximal reachable and minimal allowed values.

\section{APPLICATION TO DIFFERENT JAM POSITIONS}

Several simulation results are given here to illustrate the behavior of the proposed fault tolerant control.

Faulty case 25\%. When the EGR valve is blocked at 25\% position (widely opened), the first plot in Figure 7 shows
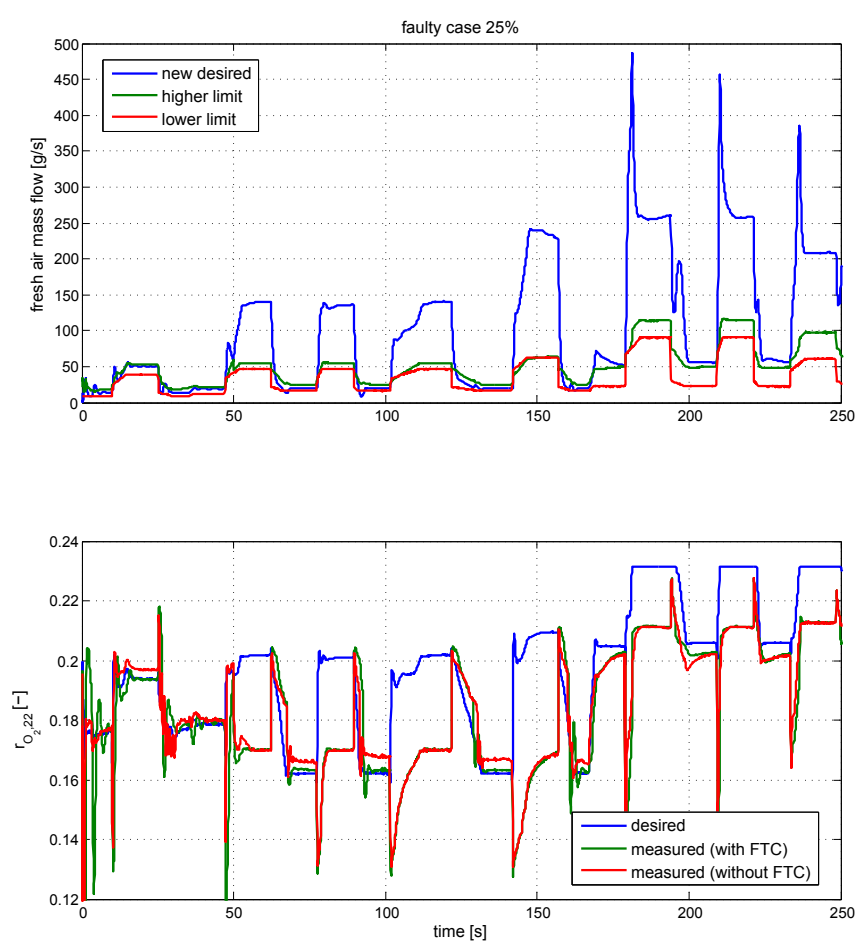

Figure 7. Faulty case 25\% at $t=50 \mathrm{~s}$. First plot: new desired fresh air mass flow with the maximal and minimal reachable values. Second plot: oxygen concentrations in the intake manifold, desired and measured (with and without FTC trajectory planning).

that the system would require much more fresh air (blue line) than the physical limit (green line) in order to reach the desired oxygen concentration in the intake manifold. A closer look at the second plot, which compares the measured oxygen concentrations in the intake manifold, shows that, most of the time, the control with model-based trajectory planning of the desired fresh air mass flow gives similar results than without it, except on the low operating points where the FTC is able to reach the desired oxygen concentration in the intake manifold.

Faulty case $50 \%$. As in the previous case, the system needs sometimes more fresh air than the maximal physically reachable value in order to reach the desired oxygen concentration in the intake manifold (Figure 8, first plot). However, in spite of the physical limitation of the system, the model-based trajectory planning of the desired fresh air mass flow makes the system reach the desired oxygen concentration in the intake manifold in the most operating regions (Figure 8, second plot), except in the full-load regions where the desired oxygen concentration requires to have only fresh air in the intake manifold, and that is not possible when the EGR valve is blocked at a middle position.

Faulty case $75 \%$. In this case, the EGR valve is blocked at $75 \%$ position, which means almost closed. Thus, less EGR gas comes into the intake manifold and the system needs less fresh air to reach the desired oxygen concentration in the intake manifold. However, the system is blocked by the $\lambda_{\text {min-limit }}$ (20) and therefore it is constrained to have more fresh air than desired in the intake manifold (Figure 9, first plot). As a consequence, the measured 

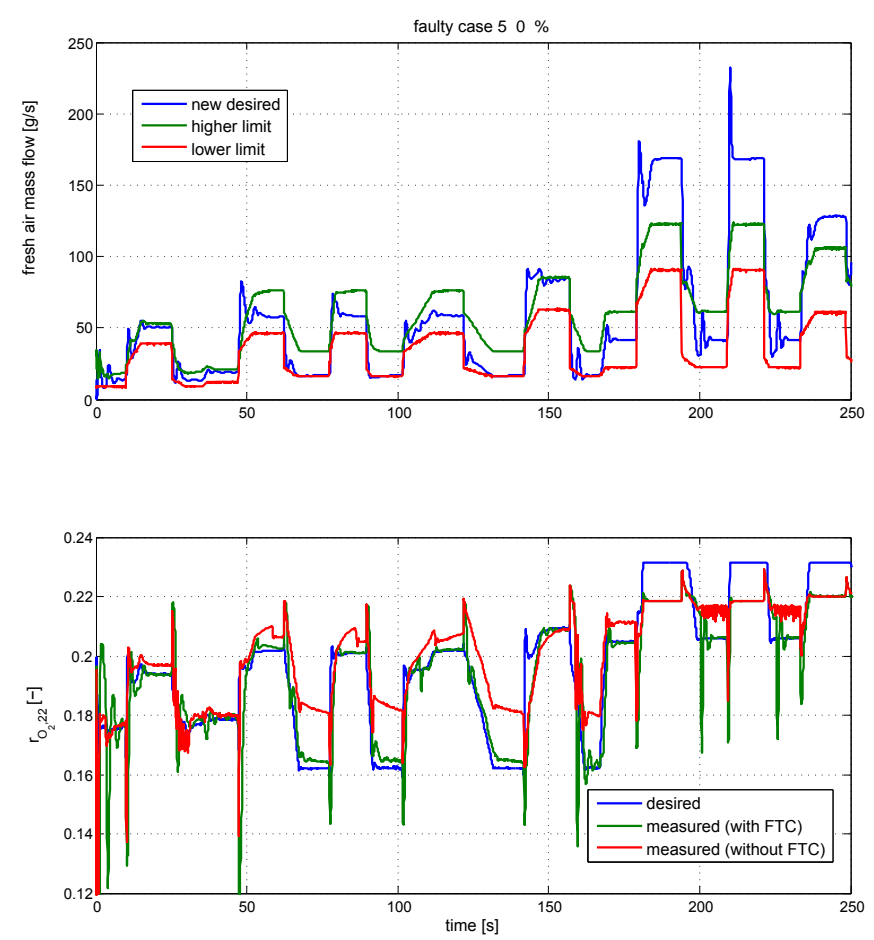

Figure 8. Faulty case $50 \%$ at $t=50 \mathrm{~s}$. First plot: new desired fresh air mass flow with the maximal and minimal reachable values. Second plot: oxygen concentrations in the intake manifold, desired and measured (with and without FTC trajectory planning).
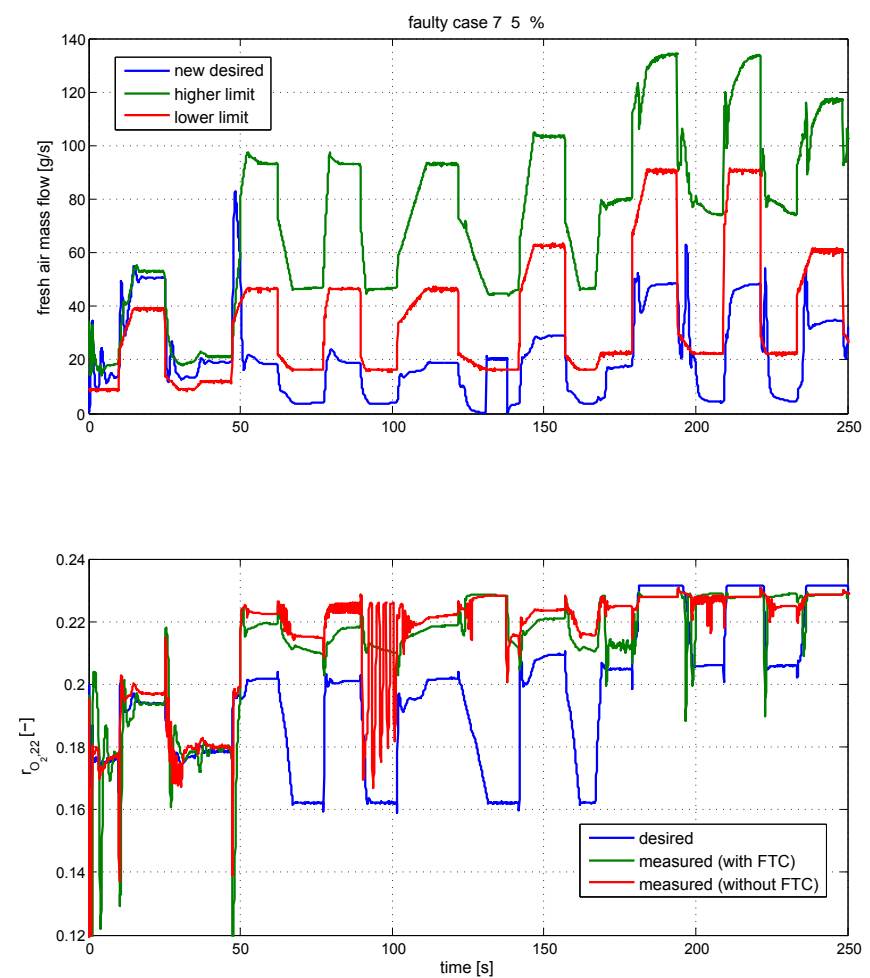

Figure 9. Faulty case $75 \%$ at $t=50 \mathrm{~s}$. First plot: new desired fresh air mass flow with the maximal and minimal reachable values. Second plot: oxygen concentrations in the intake manifold, desired and measured (with and without FTC trajectory planning). oxygen concentration in the intake manifold with FTC is greater than the desired one; however, it is lower than without FTC (Figure 9, second plot).

\section{CONCLUSION}

The model-based trajectory planning of the desired fresh air mass flow has shown many advantages. It allows to keep the same control structure, which already works pretty well in the faultless case. Furthermore, regarding the simulation results for different jam positions of the EGR valve, it has come out that this fault-tolerant control approach gives satisfactory results. Indeed, it makes the system to get closer to the desired oxygen concentration in the intake manifold than without any replanning of the fresh air mass flow trajectory.

Another additional actuator could be used in parallel to the throttle valve to improve the FTC performances. Indeed, the Variable Nozzle Turbine influences the boost pressure and therefore the oxygen concentration in the intake manifold. This would require a trajectory planning of the desired boost pressure (El Khaldi, 2009), in an analogous way of the replanning of the desired fresh air mass flow.

\section{REFERENCES}

Blanke, M., Kinnaert, M., Lunze, J., and Staroswiecki, M. (2006). Diagnosis and Fault-Tolerant Control. SpringerVerlag, Berlin.

El Khaldi, M. (2009). Fault-Tolerant Control of the Diesel Engine Air system. Master's thesis, Université Henri Poincaré Nancy 1, Robert Bosch GmbH, Dept. $\mathrm{CR} / \mathrm{AEH} 3$.

Fliess, M., Lévine, J., Martin, P., and Rouchon, P. (1992). On differentially flat nonlinear systems. In Proc. IFAC Symposium NOLCOS'92, Bordeaux, pp. 408-412.

Rothfuß, R., Rudolph, J., and Zeitz, M. (1997). Flachheit: Ein neuer Zugang zur Steuerung und Regelung nichtlinearer Systeme. Automatisierungstechnik, 45(11), 517525.

Scheu, H. (2008). Fehlertolerante Frischluftmassenregelung eines PKW-Diesel-Motors. Master's thesis, Universität Stuttgart, Robert Bosch GmbH, Dept. CR/AEH3. 